\title{
Comparing the Effect of One-way versus Two-way Tasks on Iranian Intermediate EFL Learners' Phrasal Verb Learning
}

Mohammad Reza Khodareza

Department of English, Tonekabon Branch, Islamic Azad University, Tonekabon, Iran

Gholamhossein Shabani (Corresponding author)

Department of English, Roudsar and Amlash Branch, Islamic Azad University, Roudsar, Iran

PO Box: 44817-14188

E-mail: G.Shabani762@gmail.com

Received: Dec. 29, 2015 Accepted: Jan. 25, 2015 Published: February 1, 2016

doi:10.5296/jse.v6i1.8799

URL: http://dx.doi.org/10.5296/jse.v6i1.8799

\begin{abstract}
The aim of this study was to investigate the effect of one-way and two-way tasks, as two various techniques for teaching vocabulary, on Iranian intermediate EFL learners' phrasal verb learning. The participants in this study were sixty EFL learners majoring in TEFL, all of whom were in the second semester of academic year 2015. In order to establish a homogenized group, a test of proficiency titled CELT was administered to ninety sophomore students, and sixty were selected to serve the purpose of the study. They were intermediate students with the age range within 18 to 29 . After the administration of the proficiency test as the homogeneity, they were then divided into two equal comparison groups, either of whom comprised thirty participants: one-way task (OWT) and two-way task (TWT) groups. A pretest, comprising forty multiple-choice phrasal verbs, was administered to the both groups. Then both groups underwent twelve sessions of treatment (treatment for the TWT group, and placebo for the OWT group). The OWT group was taught phrasal verbs by means of one-way task, and the TWT group was taught vocabulary via two-way tasks as input. After the treatment period, the same version of phrasal verb test was administered to both groups as posttest to examine the effectiveness of the treatment. Both groups in this study were taught by the same researcher and through the same methodology. The data were analyzed through running paired-samples and independent samples t-tests, the outcome of which revealed that
\end{abstract}




\section{Macrothink}

both the OWT group and the TWT group had vocabulary gains but the effect of two-way tasks on phrasal verbs learning was more salient than that of the one-way task group. The implications and recommendations were also presented.

Keywords: Intermediate EFL learners, One-way task, OPT, Two-way task, Phrasal verbs 


\section{Introduction}

Task-based language teaching (TBLT) is constructed on the principle that it assists learners to perform tasks through which they are assumed to be able to enhance their knowledge and skill in L2 learning along with the approach their own language learning mechanisms act as usefully as possible (Nunan, 2004). In this notion, tasks work as vehicles for generating and bringing about the conditions required for language acquisition. Ellis (2003) and Long (2015) asserted that L2 learners ought to be provided opportunities to engage them in negotiating meaning. They held that the input L2 learners receive facilitates acquisition, and the occasions they are provided enable them to use the second language more precisely and appropriately. Nunan (2004) realized tasks as valuable components in syllabus design, classroom teaching and learner assessment. In addition, Ellis (2003) introduced tasks as entities keeping a central place and position in second language acquisition research and language pedagogy. Willis (1996) appreciated tasks as practical activities occurring in learning environments where L2 learners practice the target language use to fulfill communication purposes and achieve an outcome in communication. Richards and Rodgers (2001) maintained that TBLT demands functional, interactional and structural models of language. Nunan (1999) is supportive of task-based instruction (TBI) by arguing that it benefits tasks or activities that involve comprehending, producing, manipulating or interacting in the target language. TBI assists learners in discovering communication opportunities they experience in their learning situations.

This study was designed to investigate the effect of a task-based mode of teaching on Iranian EFL intermediate learners' phrasal verb learning and enhancement. It also sought to find out whether there is any difference in learning phrasal verbs through the application of two task-based approaches including one-way versus two-way tasks. Scholars such as Breen (1987), Ruso (2007), Del La Fuente (2006), Ilin, Inuzu, and Yumru (2007) showed the effect of task-based approach to learning English as a foreign language. The findings of studies showed that tasks can be used in vocabulary classes to enhance learners' motivation and vocabulary gain. There was not, however, any empirical research in this field at the EFL community college level in Iran.

\section{Research Hypotheses}

Given the independent and dependent variables on which the study was conducted, three hypotheses were posed as follows:

H01: One-way tasks do not affect Iranian intermediate EFL learners' phrasal verb learning.

H02: Two-way tasks do not affect Iranian intermediate EFL learners' phrasal verb learning.

H03: There is no significant difference in L2 phrasal verb learning scores among Iranian intermediate EFL learners instructed by various tasks.

\section{Review of the Literature}

\subsection{Task-based Language Learning/Teaching}

Richards and Rodgers (2001) and Willis (1996) defined task-based instruction as an approach which creates learners with a learning context in which the use of the target language through 
communicative activities is highlighted and the process of using language is more important than production of correct language forms. In this notion, TBI is one model of Communicative Language Teaching (CLT) in that it focuses on real and meaningful communication as the main concern for language learning. This model of instruction, as Brumfit (1984) and Ellis (2003) stressed, appeared and flourished as an alternative method to traditional language teaching methods because it fostered a newly-developed methodology whose ultimate concern and cornerstone was functional communicative language use. Cubillo and Brenes (2009) indicated that TBI fosters learner-centered ground in which learners have the greatest role in a learning process and learners' cooperative activity and participation in groups while performing tasks have a significant role. Willis (1996) and Lee (2000) considered a task as any activity in a language learning context in which the target language is practiced by learners for a communicative purpose to arrive at an outcome. Nunan (2004) revealed that tasks possess the capacity to direct learners to the meaningful use of a foreign language in that language use is more important than language practice, and the activities that are designed involve learners in fulfilling the tasks assigned. Willis (1996) and Bygate, Skehan, and Swain (2001), and Ellis (2003) argued that tasks bring about activities involving learning beyond mere focus on language form and combining communicative language use with language form practice. Task-based Learning (TBL) is an effective approach for learning in that it supplies L2 learners with opportunities to associate old knowledge with other learning tasks communicatively. Nunan (1999) indicated that a task is viewed as a piece of work or meaningful activity occurring in classroom and involves learners in comprehending, producing or interacting in the target language in such a way that their attention is primarily focused on meaning rather than form.

Ellis (2003) pointed out five features of tasks. First, a task is referred to as an activity in teaching and learning a language requiring practice on the part of learner, in particular. It involves using the L2 learner's target language to achieve a particular purpose. Second, tasks entail meaningful activities or practice on the language form. Third, a task involves combining language use with communication purposes, creating opportunities through which learners can find grounds for meaningful interactions to achieve a particular goal. Fourth, a task uses one or a combination of various forms whose purpose is communication. Fifth, a task provides learners with opportunities and occasions that help them to grasp the use of the target language.

Willis (1996) favored text-based tasks arguing that they allow L2 learners to make use of the target language through which they are able to interpret the meanings within the text. Based upon Willis' (1996) framework of TBL, three stages about the offering of tasks are highlighted, including pre-task, task cycle, and language focus. In the pre-task stage, as Willis (1996) pointed out, the teacher explores the topic, and learners take note of useful words and phrases, and spend time on preparing for the individual task; the task cycle involves three stages labeled as task, planning, and report. At the task level, learners get involved in conducting the tasks in pairs or small groups, and the teacher controls and encourages communication among the individuals. At the planning stage, learners are prepared to report what they learn to the class, and the teacher offers language advice and clues. Through the 
report activity, students are enabled to present reports, and the educator provides feedback. The Language focus stage of task-based learning requires learners to investigate and share points on the features of the text, insert new words or phrases, and teachers play the role of reviewer and analyzer of the learning activity practiced; in addition, the teacher stresses new words and phrases followed by learners' practicing the task.

Schmitt (2000) introduced two major approaches to vocabulary acquisition which he recognized as explicit learning and incidental learning. Both types of vocabulary learning are important and interrelated. According to Schmitt (2000) and Richards and Schmidt (2002), Ahmad (2011), and Nation (2001), explicit learning involves directly focusing on word study, or intentional attempt is made to take word or words into account whereas an incidental approach of vocabulary learning requires more use of language in such a way that learning vocabulary stands as a by-product task in dealing with any skill of language inside and outside the classroom context.

Some scholars such as Nation (2001), Gass (1999), and Lotfi (2007) drew attention to the three processes of learning vocabulary realized as noticing originating from formal instruction, retrieving, and generating. These processes involve the cognate relationships between the learners' target language and first tongue that provides exposure to the language and background knowledge of vocabulary.

\subsection{Classification of Tasks}

Pica, Kanagy, and Falodun (1993) devised and offered a five-component categorization of tasks comprising jigsaw, information-gap, problem solving, decision-making and opinion exchange tasks. Jigsaw tasks involve learners to complete and construct a whole out of separate pieces of information available to them. Information-gap tasks require different participants in a group to share and interact with text information collaboratively to complete a text. Problem-solving tasks offer a problem and some separate, but interconnected pieces of useful information, out of which learners are given a chance to find a solution to the problem. Decision-making tasks need the learners in a learning context to undertake effort to make a joint decision by negotiating and discussing the solutions provided to them. Opinion exchange tasks have learners get engaged in discussions. Learners are required to share or exchange their ideas and understand others' opinions but there is no concern for achieving a joint decision. Willis (1996) introduced a classification of tasks including ordering, sorting, comparing, problem solving, sharing personal experiences, and creative tasks. Meanwhile, Rashtchi and Keyvanfar's (2007) classification of tasks involves form-focused activities, meaning-focused tasks, focused tasks, grammatical tasks, consciousness-raising tasks, unfocused tasks, pedagogic tasks which are interactionally authentic, information-gap activities, opinion-gap tasks, reasoning-gap tasks, and target tasks which are situationally authentic. There is a distinction between focused and unfocused tasks in terms of their nature. Rashtchi and Keyvanfar (2007) showed that focused tasks provide the opportunity for fostering communicative language use and encouraging L2 learners' tendency for practicing some specific predetermined linguistics items and norms. Unfocused tasks, based on what Bachman (1991) argued, are recognized and described in terms of the degree to which they 
appear similar to real-life situations and contexts. The interpretation of this idea is that some tasks are found to possess situational authenticity in that they correspond to learners' everyday lives. Some other tasks, in turn, may not occur or are unlikely to be represented in learners' daily lives which are therefore interpreted as artificial tasks. They are realized as artificial tasks since they represent some kinds of language forms looking like the language of everyday-life interaction. These kinds of pedagogic tasks, as Bachman (1991) clarified, are interactionally authentic. A somewhat different categorization of tasks is Nunan's (2001) classification of task types that comprise two-component tasks termed as pedagogic and real-world ones. Pedagogic tasks are referred to as communicative ones for the sake of clear communication purposes in the classroom as an instrumental or instructional goal. The real-world tasks employ the target language features and norms commonly used outside the classroom in the real world.

\subsection{Two-way Tasks versus One-way Tasks}

Two-way tasks are contrasted with one-way tasks in that in the former learners are provided opportunity for group work or collective activities so that they can help to complete a task. The two-way tasks allow for interaction among participants and share of responsibility among learners to get involved in a learning activity in order to complete the task. There is a variety of two-way tasks, out of which, we name: jigsaw activity in which each individual holds a part or a piece of the information needed to complete the task; running dictation; text reconstruction; comprehension task; conscious raising tasks; convergent and divergent tasks; cue-card activity; and jigsaw puzzle. Ellis (2003), Izumi and Izumi (2004), and Mackey (2012) pointed out that a two-way task teaching method has the participants in any learning activity share information with the aim of fulfilling goal which is the completion of the task.

In the one-way tasks approach, as Ellis (2003), Izumi and Izumi (2004) and Mackey (2012) put forth, no interaction takes place between or among learners in a learning environment to complete a task or achieve a goal. It is also assumed that there is no share of responsibility between two individuals or among learners as a collective work plan to complete a task. Within the domain of one-way task, information is held by a single person and there is no chance for negotiation of meaning or interaction between students. Every individual is personally assigned to work on a task. Mackey (2012) suggested non-reciprocity in the case of one-way task, holding that one-way tasks involve no transfer of information or interaction and learner individually takes the burden of completing the task. Examples of one-way tasks include listen-and-do tasks, fill-in-blanks exercises, translation, and telling a personal story. According to Iwashita (2001), one-way tasks offer chances which bring about producing more modified output than two-way tasks.

\subsection{Previous Research Studies and Findings}

Zarei and Sahami Gilani (2013) shed light on effects of selected collaborative techniques on Iranian intermediate EFL learners' L2 vocabulary comprehension and production. The collaborative techniques applied in this study comprised Jigsaw, Rotating Circles, Snowball, Think-Pair-Square, and Word Webbing. The findings indicated that word webbing was the 
most effective task on both vocabulary comprehension and production. Daghari and Gorjian (2015) examined the impact of applying picture-cued tasks on the learning and recall of

EFL intermediate phrasal verbs. To this end, the intermediate learners were taught phrasal verbs utilizing picture-cued tasks as their treatment, the finding of which revealed that the improvement of learners' phrasal verbs was as a result of being exposed to a picture-cued task. Thus the picture-cued tasks could affect the participants' retention and recall significantly. Behzadi and Azimi Amoli (2014) made an attempt to investigate the impact of two task types including context learning condition versus translation learning condition. That study targeted Iranian intermediate learners majoring in TEFL. It was concluded that the context learning condition was more beneficial than the translation learning condition on enhancing Iranian EFL learners' phrasal verb learning. Najafi Karimi, Birjandiand Alavi's (2015)study was to investigate the effectiveness of two types of output tasks (cloze and editing) in individual and collaborative conditions on the acquisition of English phrasal verbs. The research study incorporated Iranian intermediate EFL learners, majoring in TEFL, as the target participants. Results of the research work revealed that the subjects performed significantly better on collaborative output tasks than on individual output tasks in learning the target phrasal verbs. It was then concluded that the collaborative output task was more effective than the individual output task concerning its impact on enhancing EFL learners' phrasal verb learning.

Birjandi, Alavi, and Najafi Karimi (2015) conducted a study to examine the relative effectiveness of three types of input including unenhanced input, typographically enhanced input and lexically elaborated input on learning English phrasal verbs on Iranian intermediate EFL learners. They reported that typographical input enhancement was more effective than unenhanced input on learning English phrasal verbs, and that lexically elaborated input elaboration produced better effect than unenhanced input, and finally elaborated lexical input was shown the most effective of all in helping L2 learners to learn English phrasal verb. Zohouri Vaghei, Taghipour Bazargani, and Pourramzan (2015) investigated the degree of effectiveness of two types of tasks including one-way versus two-way tasks on Iranian intermediate EFL learners' collocation competence (lexical collocation learning). What they reported as the main findings of this study was representative of the efficacy of two-way tasks over the one-way tasks. In other words, the findings of this study revealed that incorporating tasks, in particular, two-way task-based activities in EFL classrooms enhance L2 learners' acquisition of lexical collocations.

\section{Methodology}

\subsection{Participants}

The participants in this study were 60 intermediate EFL university students, majoring in TEFL at the Islamic Azad University of Roudsar and Amlash, Iran. They were composed of both male and female. Twenty-five of the participants were male and thirty-five were female whose age ranged from 18 to 29. All the participants' first language was Persian. To establish a homogenized group, the participants were exposed to the Comprehensive English Language Test (CELT) as a proficiency test. In general, the CELT test was administered to ninety 
students out of whom sixty were selected in accordance with the results of the test. Those students whose scores were measured one standard deviation above and below the mean (i.e., mean $\mp 1)$ were selected as target participants to serve the purpose of the study. They were randomly assigned into two equal comparison groups, including one-way task $(\mathrm{OWT}=30)$ and two-way task $(\mathrm{TWT}=30)$ groups.

\subsection{Materials and Instruments}

The materials and instruments applied in this study were of four types as follows:

\subsubsection{The Comprehensive English Language Test (CELT)}

The CELT sheds light on the learners' language level. This test provided the instructors with a reliable and efficient means of placing the learners at the start of a course. This means that usually before taking part in one of the English courses, EFL learners take a CELT which helps the teachers identify their proficiency level.

In order to keep the homogeneity of the participants under study, a multiple-choice-item CELT was administered to 90 students. Based on the CELT results, the participants whose score range was one standard deviation above and below the mean (i.e., mean \pm 1 ) were assigned and recognized as being at intermediate level and were selected as the participants of this study.

\subsubsection{Pretest of Phrasal Verbs}

The pretest to which the participants were exposed was a vocabulary test that comprised forty multiple-choice phrasal verb items (recognition type). The test on phrasal verbs was constructed using the materials from two native-like course-books on vocabulary/phrasal verbs titled 'English Phrasal Verbs in Use" by McCarthy and O'Dell (2007) and Intermediate Vocabulary by Thomas (2013), both of which were used as course-books to university students majoring in TEFL.

\subsubsection{Posttest of Phrasal Verbs}

This test which was administered after the treatment sessions was equal in all respects to pretest except for the arrangement of some items. To this end, the same version of phrasal verb multiple-choice-item test was given as a posttest to the both groups of participants. It is worth mentioning that some items of the test in the posttest were rearranged, the primary purpose of which was to reduce or avoid the testing effect and subjectivity.

\subsubsection{Pilot Study}

The vocabulary test, comprising forty items, was constructed and given as the pretest and posttest of this study. It underwent a pilot study. In doing so, a 40 -multiple-choice-item vocabulary test on phrasal verbs including 62 items, which was constructed from two native sources titled 'Intermediate Vocabulary' by Thomas (2013) and 'English Phrasal Verbs in Use' by McCarthy and O’Dell (2007), was administered to thirty EFL students having similar 
characteristics as those of the target groups. Taking the psychometric characteristics of the items, namely, item facility, item discrimination, and choice distribution, the poor items of the test were omitted from the final version, after which a 20- multiple-choice-item vocabulary test consisting of the target 20 items was established and considered as the pre-test and post-test to serve the requirement of the study.

\subsubsection{The Material for the Treatment}

Both the OWT and TWT groups received treatment (treatment for the TWT group participants and placebo for the OWT group). Both groups involved underwent treatment based on the same methodology, through the same material, and within the same time period. The material assigned in the treatment sessions for both groups comprised twenty-four reading passages, each of which included 180 to 200 words. The readability of the selected passages was determined based on Fog's readability formula (about 19.80). The passages did not involve culture-specific or discipline-specific background knowledge. They were all authentic passages and selected from English language teaching materials considered appropriate for intermediate EFL learners. Each text included eight to ten phrasal verbs which provided the participants with practice during each session of treatment. The new phrasal verbs were equally enhanced so that the participants could focus on them while practicing them through the required tasks.

\subsection{Data Collection Procedures}

This study was conducted in the second term of the academic year 2015. The participants were all university students majoring in TEFL. Their first language was Persian. Upon administering the test of homogeneity whose purpose was to keep a homogenized group, sixty participants out of ninety subjects were selected through the CELT. Among these participants who passed the exam, the ones who could obtain the score one SD above and below the mean were selected for the study. Therefore, 60 participants remained and the scores of other students were excluded from the data analysis in the remaining phases of this study (i.e., pretest and posttest). The participants were randomly assigned into two equal comparison groups, both of which comprised thirty participants $(\mathrm{OWT}=30$, TWT $=30)$. The pretest piloted before, with a reliability index of 0.78 , was then administered. It required the participants to answer the questions concerned with phrasal verbs represented through multiple-choice-items. Then, both of the comparison groups received a 12-session treatment through which the participants in the TWT group encountered phrasal verb exercises embedded into texts where they were asked to practice and learn them through two-way tasks in their classes. The two-way tasks which were applied for this group as inner-class activity were jigsaw, cue-card, and Rotating Circles which obligated the participants to work collectively and actively participate to complete the task. These activities had them each hold part of the information and share knowledge needed to complete the task.

The participants in the OWT group (as the other comparison group)were provided a 12-session placebo during which they encountered phrasal verb exercises represented in the same texts, according to which they were supposed to deal with and learn the new phrasal verbs, given in the passages, via one-way tasks offered to them. The techniques which were 
adopted and practiced to fulfill the requirement of this group were blank-filling exercise, Listen-and-do tasks, and picture-cued attempt. The application of this task was to place the burden of completing the task successfully on the individual participant who held the information. To do so, the participants were supposed to work on two pieces of texts, for each session, in which the new phrasal verbs were given in fill-in-blank forms. They were given chance to fill in the blanks with the phrasal verbs provided. The participants of the two groups were provided a chance to make use of monolingual dictionaries to look up the words and deal with their meanings.

The two comparison groups received treatment (treatment for the TWT group and placebo for the OWT group) via the same methodology and the same materials in the same period of time. At the end of these twelve sessions, a posttest of phrasal verbs was administered. It was equal in all respects to the pretest expect for the arrangement of some items. This rearrangement was purposefully done to control for the probable testing effect. An independent-samples t-test was conducted to compare the means of the TWT group and OWT group scores in the posttest with the alpha set at 0.05 . In addition to running an independent samples t-test for the posttest scores of the two groups, two paired-samples t-tests were also used in this study.

\subsection{Design}

All requirements of a quasi-experimental study, including pretest, posttest, randomization, treatment for the TWT group and placebo for the OWT group were met in this study. The independent variables of the study were two-way tasks and one-way tasks, and the dependent variable was L2 phrasal verb learning.

\subsection{Data Analysis}

The present study was constructed and designed based on three null hypotheses, incorporating three variables out of which one stood as the dependent variable and two other as independent variables. The quantitative data collected were analyzed by means of the Statistical Package for the Social Sciences (SPSS) for Windows version 16.One independent-samples t-test was run to compare the posttest scores of the two groups. In addition, two paired- samples t-tests were run to test the null hypotheses of the study and the alpha level for significance testing was set at .05.

\subsection{Results}

This section provided a report and illustrated the analysis of the collected data to test the research hypotheses formulated for the purpose of this study.

\subsubsection{Testing the First Null Hypothesis}

The first null hypothesis of this study addressed that "One-way tasks do not affect Iranian intermediate EFL learners' phrasal verb learning". To investigate this hypothesis, a paired-samples t-test was conducted. The descriptive statistics are represented in Table 1. 
Table 1. Descriptive Statistics of the Paired-Samples t-test for the OWT (One-way Task) Group

\begin{tabular}{cccccc}
\hline & & & Std. & $\begin{array}{c}\text { Std. } \\
\text { Deviation }\end{array}$ & Error Mean \\
\hline \multirow{2}{*}{ Pair 1 } & PreCON & 12.20 & 30 & 3.95 & .76 \\
& PostCON & 13.72 & 30 & 2.80 & .54 \\
\hline
\end{tabular}

The result of conducting a paired-samples t-test to examine the first null hypothesis, as represented in Table 1, indicated that the posttest mean score of the OWT (One-way Task) group which equaled 13.72 was higher than the pretest mean score (12.20) of the group. The standard deviation for the posttest was measured and determined to be less than the pretest. It can, accordingly, be inferred that there was less variability among OWT group's posttest scores compared with the pretest scores.

In order to find out whether there was a significant difference between the pretest and posttest mean scores of the OWT group, the results of a paired-samples t-test are presented in Table 2.

Table 2. Descriptive Statistics of Paired Differences (OWT Group)

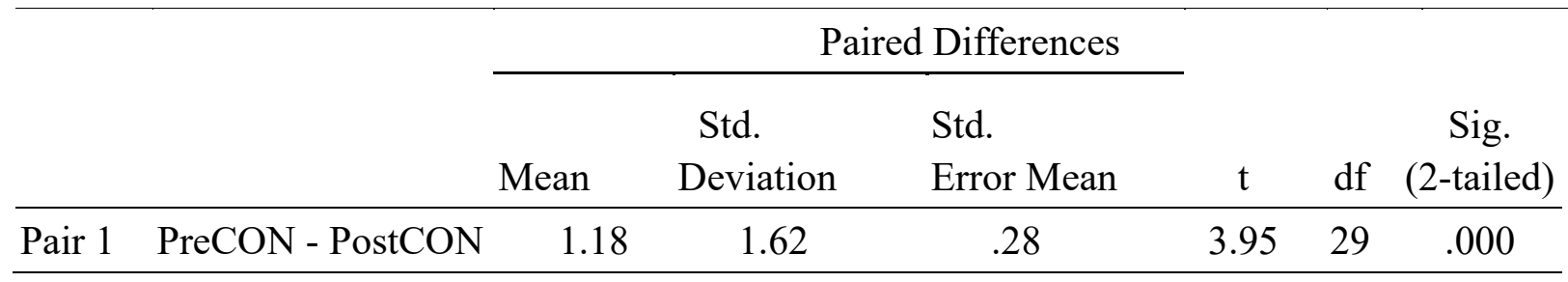

It can be seen in Table 2 that the scores on pre/posttest were different. The means and standard deviations of scores of pre/posttest were estimated and these revealed the difference between pre/posttest of the first group. As shown in Table 2, there was a significant difference, $t(29)=3.95, p=.000)$, between the pretest-posttest mean scores of the CT group. Accordingly, the first null hypothesis of the study was rejected.

\subsubsection{Testing the Second Null Hypothesis}

The second hypothesis of the study predicted that "Two-way tasks do not affect Iranian intermediate EFL learners' phrasal verb learning". To examine the accuracy of this null hypothesis, a paired-samples t-test was run regarding the Two-way Task (TWT) group, the result of which is illustrated in Table 3.

Table 3. Descriptive Statistics of Paired-Samples t-test for the TWT (Two-way Task) Group

\begin{tabular}{cccccc}
\hline & & & & $\begin{array}{c}\text { Std. } \\
\text { Deviation }\end{array}$ & $\begin{array}{c}\text { Std. Error } \\
\text { Mean }\end{array}$ \\
\hline \multirow{2}{*}{ Pair 1 } & PreEX & 12.60 & 30 & 3.98 & .72 \\
& PosEX & 15.85 & 30 & 2.45 & .44 \\
\hline
\end{tabular}




\section{Al Macrothink}

The results of the t-tests, illustrated in Table 3, showed that there was a statistically significant difference between the pretest/posttest mean scores of the TWT group (Posttest Mean $=15.85>$ Pretest Mean $=12.60$ ). To conclude, the TWT participants' gain in phrasal verbs after the treatment was notable. This difference in the mean from the pretest to posttest indicated the rejection of the second null hypothesis. Furthermore, standard deviation (Std. Deviation) for the posttest in this group was less than that of the pretest, which showed less variability among the TWT group's posttest scores than that of the pretest.

To find out if this difference was significant, the result of the second paired-samples t-test in Table 4 provides further information on the second null hypothesis.

Table 4. Paired -Samples t-test for the TWT Group

\begin{tabular}{ccccccc} 
& \multicolumn{4}{c}{ Paired Differences } & & Sig. \\
\cline { 2 - 4 } & Mean & $\begin{array}{c}\text { Std. } \\
\text { Deviation }\end{array}$ & $\begin{array}{c}\text { Std. } \\
\text { Error Mean }\end{array}$ & T & df & $\begin{array}{c}\text { S-tailed) } \\
\text { (2-tailed }\end{array}$ \\
\hline PreEX - PosEX & 3.40 & 1.77 & .34 & 10.48 & 29 & .000 \\
\hline
\end{tabular}

Table 4 shows that there was a significant difference, $\mathrm{t}(29)=10.48, \mathrm{p}=.00)$, between the pretest-posttest mean scores of the TWT Group. By referring to the figures given in Table 4 extracted from running a paired-samples t-test, the second null hypothesis of the study, which predicted that two-way tasks do not affect Iranian intermediate EFL learners' phrasal verb learning, was rejected.

\subsubsection{Third Null Hypothesis}

The third null hypothesis formulated for this study claimed that there was no significant difference in the phrasal verb gain of the OWT input group and TWT group instructed by either two-way tasks or one-way tasks. To examine what the null hypothesis predicted, an independent-samples t-test was run. The descriptive statistics of the results are represented in Table 5.

Table 5. Descriptive Statistics for the OWT and TWT Groups in the Posttest

\begin{tabular}{|c|c|c|c|c|c|}
\hline & Readingtext & $\mathrm{N}$ & Mean & $\begin{array}{c}\text { Std. } \\
\text { Deviation }\end{array}$ & $\begin{array}{c}\text { Std. } \\
\text { Error Mean }\end{array}$ \\
\hline \multirow[b]{2}{*}{ Phrasal Verbs } & Two-way task & 30 & 15.85 & 2.45 & .44 \\
\hline & One-way task & 30 & 13.72 & 2.80 & .54 \\
\hline
\end{tabular}

The results of the t-tests, illustrated in Table 5, indicated that there is a statistically significant difference between the OWT group and TWT group posttest mean scores. Comparatively, the post test mean score of the OWT group in the posttest was 13.72 while the mean for the TWT group was 15.85 . The standard deviation value for the TWT group was less than the other 
group, denoting that there was less variability in the scores of the TWT group's participants than those of the OWT group's participants. The results showed that the TWT group outperformed the OWT group, indicating that two-way tasks instruction resulted in more fruitful gain in EFL intermediate learners' phrasal verb production. Thus, the third null hypothesis predicting that there was no significant difference in L2 phrasal verb learning scores among Iranian intermediate EFL learners instructed by various tasks was rejected.

To find out whether there was a significant difference between the two groups' posttest mean scores, the results of the independent-samples t-test are given in Table 6.

Table 6. Independent-Samples t-test for the OWT and TWT Groups in the Posttest

\begin{tabular}{|c|c|c|c|c|c|c|}
\hline & & \multicolumn{5}{|c|}{ t-test for Equality of Means } \\
\hline & & \multirow[b]{2}{*}{$\mathrm{t}$} & \multirow[b]{2}{*}{$\mathrm{df}$} & \multirow{2}{*}{$\begin{array}{c}\text { Sig. } \\
\text { (2-tailed) }\end{array}$} & \multicolumn{2}{|c|}{$\begin{array}{c}95 \% \text { Confidence } \\
\text { Interval of } \\
\text { the Difference }\end{array}$} \\
\hline & & & & & Lower & Upper \\
\hline \multirow{2}{*}{$\begin{array}{l}\text { Phrasal } \\
\text { Verbs }\end{array}$} & $\begin{array}{l}\text { Equal variances } \\
\text { assumed }\end{array}$ & 3.16 & 58 & .003 & .74 & 3.51 \\
\hline & Equal variances not assumed & 3.16 & 57.16 & .003 & .74 & 3.51 \\
\hline
\end{tabular}

Table 6 shows that there is a significant difference, $\mathrm{t}(58)=3.13, \mathrm{p}=.003$, between the OWT and TWT groups. Then, the third null hypothesis of the study was rejected.

\section{Discussion}

This study was an attempt to examine the impact of two models of tasks, including two-way versus one-way, which stand as two vocabulary learning techniques in EFL contexts on Iranian intermediate EFL learners' phrasal verb gain. The results obtained from the data analysis procedure provided a vivid answer that applying a two-way task-based approach to teaching phrasal verbs can enhance more effectively the EFL participants' recognition of phrasal verbs and vocabulary gain. The findings of this study were primarily supportive of the significant role played by the utilization of two-way tasks tendency in the development of EFL learners' phrasal verb capacity. The results of this study, furthermore, revealed that the two-way tasks input and one-way-task input were both effective on EFL Learners' vocabulary learning, but the tendency was more notably directed at the application of the two-way task-based approach in terms of its significant effect on Iranian intermediate EFL learners' phrasal verb gain compared with the involvement of one-way task-based input. It appeared that the participants being exposed to a presentation of two-way task exercises experienced more effective gain in their overall improvement in phrasal verbs. According to this research study, L2 vocabulary learning capacity can be enhanced as learners are exposed to tasks demanding their collaborative participation, encouraging them to get involved in learning 
contexts allowing for the burden of responsibility shared by the group members. In other words, each participant of a group assumes the responsibility for a part or piece of the whole task in order to complete the task. This idea is in line with what was put forward in Pica's (1994) approach, maintaining that as more competent interlocutors interact with less competent speakers, they undertake an effort or deliberately make an attempt to reformulate what they think they mean through offering very specific feedback on a problem item. The participants who were exposed to two-way task-based approach treatment activities showed a meaningful difference and outperformed the participants who encountered one-way task and activities due to the treatment effect. This was in line with Ellis's (2003) notion who favors task-based instruction as a successful and fruitful approach to second/foreign language teaching which entails the enforcement and implementation of various tasks to generate effective results in L2 learning contexts. Meanwhile, Richards and Rodgers (2001) called task-based approach with its great variety of tasks the cornerstone of planning and instruction in language teaching. Nemat Tabrizi (2011) referred to one of the most effective privileges of task-based approach to language learning and teaching, accounted for by its capacity for socially driven development of language and its skills, and this aspect of the task-based approach corresponds to Vygotskian accounts of language learning. In other words, it is held that, the more opportunities available for negotiation and interaction, the more likely acquisition is to happen.

The findings of this study stand in line with Zarei and Sahami Gilani's (2013) research findings, through which they revealed that EFL learners' exposure to collaborative techniques of Jigsaw, Rotating Circles, Snowball, Think-Pair-Square, and Word Webbing resulted in more effectiveness in EFL learners' vocabulary comprehension and production. The findings of the present study are in accordance with Najafi Karimi, Birjandi and Alavi's (2015) result indicating that the collaborative output task was more effective than individual output task in terms of its impact on enhancing EFL learners' phrasal verb learning. Furthermore, the findings of the study supported Behzadi and Azimi Amoli's (2014) field of research work, the result of which indicated that out of two tasks of context learning condition versus translation learning condition regarding their effectiveness on Iranian intermediate EFL learners' phrasal verbenhancement, the former was found to be more beneficial to learners' phrasal verb learning. The findings of this research work are, however, inconsistent with what Daghari and Gorjian (2015) reported through their research result. Through investigating the impact of picture-cued tasks on the learning and recall of EFL intermediate phrasal verbs, they made known that the picture-cued task was more effective on the intermediate learners' phrasal verbs. Furthermore, our study results are consistent with Zohouri Vaghei, Taghipour Bazargani, and Pourramzan's (2015) research findings, by which they did a comparative study on the impact of one-way versus two-way tasks on Iranian Intermediate EFL learners' collocation. The result of their attempt was indicative of the efficacy of two-way tasks on enhancing and enriching learners' knowledge of L2 collocation.

\section{Conclusion}

The experimental findings of this study evidenced better performance of the participants who encountered two-way task treatment. The two-way task-based activities were found to be 
more effective and influential than the one-way task-based input as to their impact on Iranian EFL intermediate phrasal verb development. Being integrated into learning contexts fostered by collaborative tasks and interactive activities facilitates L2 learners' burden of completing a task and leads to improved learning of vocabulary. This approach, which allows for the sharing of responsibility among participants to fulfill an aim in a learning environment, culminates in learners' better performance and effective gain in vocabulary learning. According to Blake (2000), two-way tasks bring about further negotiation of meaning than other task types, and this characteristic is due to their convergent nature. In addition, two-way tasks possess significant features such as more confirmation checks, comprehension checks, and clarification requests made in learning contexts. Lin (2009) and Batanfar and Hashemi (2010) noted that a task-based approach helps learners internalize language skills in a natural manner and assists learners how to sort out and figure out the problems that they may encounter in real life. In two-way tasks, all the participants are obligated to participate in order to complete the task. According to Ddeubell (2015), two-way tasks, which are also known as "information gap" activities, encourage students to interact with each other to retrieve information to complete a task. A fundamental field of interest, as Robinson (2001) and Skehan (1998) hold, in the domain of cognitive perspective is concerned with investigating the manner with which cognitive requirements of tasks affect learners' intentional resources and language performance. Thus, providing EFL foreign learners with a list of words represented through the implementation of two-way tasks and activities which require cognitive commands assists their effective performance.

The findings of this study are beneficial in many ways and pave the way in the arena of task-based language learning and teaching. To this end, the results of this study are beneficial to L2 learners, language teachers, and curriculum designers. The results obtained from this study shed light on applicability of two-way activities in teaching words, in particular, phrasal verbs. By implementing interactional and communicative tasks such as jigsaw puzzle, cue-card activity, memorizing cards, jumbled sentences (in pair and group) and some others which could facilitate learning collectively instead of individually, phrasal verbs learning will be enhanced. Two-way tasks can help students pay attention to different words which string together and raise their awareness. Using two-way tasks provides the potential for more negotiation for meaning, interaction, communication, cooperation and collaboration, all of which could be effective to create an atmosphere where learners could attain high language proficiency and move forward to this aim faster. Curriculum and syllabus designers, material and curriculum developers can benefit from the findings of this study, as well. They can incorporate TBLT-based instruction more than status quo, and it is fruitful for stakeholders such as students, teachers, learners, lecturers, teacher trainers, researchers, and professors.

The present study was an attempt to examine the effectiveness of two models of tasks (two-ways tasks versus one-way tasks) on Iranian intermediate EFL phrasal verb enhancement. Future studies of a similar nature can incorporate the effect of these two tasks on L2 learners' other skills of learning such as speaking with its various components or sub-skills, listening with its variety of subcomponents, and grammar enhancement 
considering its wide variety of subcategories. Such studies can target higher proficiency levels including post-intermediate and advanced students in EFL context.

\section{References}

Ahmad, J. (2011). Intentional versus incidental vocabulary learning. Interdisciplinary Journal of Contemporary Research in Business, 3(5), 67-75.

Batanfar, A., Hashemi, T. (2010). Vocabulary Learning Strategies and ELT Materials.A Study of the Extent to Which VLS Research Informs Local Course-books in Iran. International Education Studies.89(1), 76-91

Birjandi, P., Alavi, S. M. \& Najafi Karimi, S. (2015). Effects of unenhanced, enhanced, and elaborated input on learning English phrasal verbs. International Journal of Research Studies in Language Learning, 4(1), 43-59.

Bachman, L. F. (1991). What does language testing have to offer? TESOL Quarterly, 25(4), 671704.

Breen, M. (1989). The evaluation cycle for language learning tasks. In R. K. Johnson. The Second Language Curriculum. (p. 187-206). Oxford: Oxford University Press.

Bygate, M., Skehan, P., \& Swain, M. (2001). Researching pedagogic language learning, teaching and testing. Harlow, England: Longman.

Behzadi, A. \& Azimi Amoli, F. (2014). The Effect of Task Types on Learning Phrasal Verbs among Iranian EFL Learners. Journal of Social Issues and Humanities, 2(2), 52-56.

Brumfit, C. J. (1984). Communicative Methodology in Language Teaching. Cambridge: Cambridge University Press.

Cubillo, P., \& Brenes, C. (2009). Using task-based instruction in ESP course in the computer center at the University of Costa Rica. INIE Journal of Costa Rica University, 9(1), 1-25.

Daghari, Z. \& Bahman, G. (2015). The effect of picture-cued tasks on the acquisition and recall of separable and inseparable phrasal verbs by pre-intermediate Iranian EFL learners. International Journal of Language Learning and Applied Linguistics World, 8(4), 32-46.

de la Fuente, M. J. (2006). Classroom L2 vocabulary acquisition: Investigating the role of pedagogical tasks and form-focused instruction. Language Teaching Research, 10(3), 263-295.

de la Fuente, M. J. (2002). Negotiation and oral acquisition of L2 vocabulary: The roles of input and output in the receptive and productive acquisition of words. Studies in Second Language Acquisition, 24, 81-112.

Ellis, R. (2003). Task-based language teaching and learning. New York: Oxford University Press.

Gass, S. (1999). Discussion: Incidental vocabulary learning. Studies in Second Language Acquisition, 21(2), 319-333. http://dx.doi.org/10.1017/S0272263199002090 
İlïn, G., İnözü, J., \& Yumru, H. (2007). Teachers' and learners' perceptions of tasks: Objectives and outcomes. Journal of Theory and Practice in Education, 3(1), 60-68.

Izumi, Y., \& Izumi, S. (2004). Investigating the effects of oral output on the learning of relative clauses in English: Issues in the psycholinguistic requirements for effective output tasks. Canadian Modern Language Review, 60(5), 587-609.

Lee, J. F. (2000). Tasks and Communicating in Language Classrooms. United States of America: McGraw Hill.

Lin, Y. P. (2002). The Effects of Collocation Instruction on English Vocabulary Development of Junior High School Students in Taiwan. (Unpublished master thesis). National Kaohsiung Normal University, Kaohsiung, Taiwan.

Lotfi, G. (2007). Learning Vocabulary in EFL Contexts through Vocabulary Learning Strategies. DOAJ Directory of Open Access Journals, 84-91.

Mackey, A. (2012). Input, interaction and corrective feedback in L2 classrooms. Oxford: Oxford University Press.

McCarthy, M. \& O’Dell, F. (2007). English phrasal verbs in use. Cambridge: Cambridge University Press.

Najafi Karimi1, S., Birjandi, P. \& Alavi, S. M. (2015). A study of the relative effectiveness of individual and collaborative output tasks on the acquisition of English phrasal verbs. Indian Journal of Fundamental and Applied Life Sciences, 5(S2), 1396-1405.

Nemat Tabrizi, A. R. (2011). The effect of using task-Based activities on speaking proficiency of EFL learners, The Asian Conference on Education Official Conference Proceedings 2011 ISSN: 2186-5892 Proceedings URL: http://iafor.org/ace_proceedings.html

Nation, I. S. P. (2001). Learning vocabulary in another language. Cambridge, England: Cambridge University Press.

Nunan, D. (1999). Language Teaching and Methodology. London: Prentice Hall.

Pica, T. (1994). Research on Negotiation: What does it reveal about second language learning conditions, processes, and outcomes? Language Learning,44, 493-527.

Pica, T., Young, R., \& Doughty, C. (1987). The impact of interaction on comprehension. Tesol Quarterly, 21, 737-758.

Richards, J. C., \& Schmidt, R. W. (2002). Longman dictionary of language teaching and applied linguistics (3rd. ed.). London, England: Longman.

Richards, J. C., \& Rogers, T. S. (2001). Approaches and methods in language teaching (2nd Ed.). Cambridge: Cambridge University Press.

Rashtchi, M., \& Keyvanfar, K. (2007). ELT Quick'n'easy (3 ${ }^{\text {rd }}$ ed.). Rahnama Publication: Tehran. 


\section{Macrothink}

Journal of Studies in Education

ISSN 2162-6952 2016, Vol. 6, No. 1

Richards, J. C., \& Rodgers, T. S. (2001). Approaches and methods in language teaching (2nd ed.).Cambridge: Cambridge University Press.

Robinson, P. (2001). Task complexity, task difficulty, and task production: Exploring Interactions in a componential framework. Applied Linguistics, 22, 27-57.http://dx.doi.org/10.1093/applin/22.1.27

Ruso, N. (2007). The influence of task based learning on EFL classrooms. Asian EFL Journal, $18,42-54$.

Skehan, P. (1998a). Task-based instruction. Annual Review of Applied Linguistics, 18, 268-286. http://dx.doi.org/10.1017/S0267190500003585

Schmitt, N. (2000). Vocabulary in language teaching. Cambridge, England: Cambridge University Press.

Thomas, B. J. (2013). Intermediate Vocabulary. Iran: Arvin Language Development Publications.

Willis, J. (1996). A framework for task-based learning. Harlow, England: Longman.

Willis, D. (1990). The lexical approach. New York, NY: Language Teaching Publication.

Zarei, A. A., \& Sahami Gilani, M. (2015). L2 vocabulary learning through collaborative techniques. International Journal of Language Learning and Applied Linguistics World, $4(1), 71-84$.

Zohouri Vaghei, A., Taghipour Bazargani, D., \& Pourramzan P. (2015). The effect of one-way versus two-way tasks on Iranian Intermediate EFL learners' collocation competence (Unpublished Master Thesis). Islamic Azad University, Rasht Branch, Iran. 